\title{
EFEITO DO TEOR DE GORDURA NAS PROPRIEDADES ÓPTICAS DO LEITE
}

\author{
J. N. R. COSTA, A. F. G. MONTE e F. R. X. BATISTA \\ Universidade Federal de Uberlândia, Faculdade de Engenharia Química \\ E-mail para contato: juranzatti@ufu.br
}

\begin{abstract}
RESUMO - A ingestão de leite e seus derivados é recorrente na dieta alimentar da população devido ao seu valor nutritivo. Além de ser uma fonte rica em proteínas e vitaminas que auxiliam na construção e preservação de tecidos e músculos, o leite é fonte de minerais que contribuem para o processo de cicatrização e fortalecimento dos ossos. A concentração de gordura do leite in natura pode variar de $2,8 \%$ a $6,5 \%$ conforme a raça e genética do animal, alimentação, estágio de lactação, entre outros fatores. Deste modo a implantação de novas tecnologias como sensores ópticos auxiliam na determinação do teor de gordura para assessorar a seleção e orientação nutricional dos rebanhos, bem como viabilizar a padronização do leite em virtude da sua aplicação comercial e industrial, deve ser considerada. O presente trabalho teve como objetivo utilizar a esfera integradora para analisar o efeito do teor de gordura do leite (UHT integral e desnatado), nos valores de coeficiente de absorção e espalhamento.
\end{abstract}

\section{INTRODUÇÃO}

O leite é composto majoritariamente por água (87\%), além de proteínas, vitaminas, sais minerais e uma pequena porcentagem de gordura, que difere para cada classificação. A gordura no leite é retida na forma de suspensão presente na fase aquosa, uma vez que os glóbulos são impedidos de aglutinar devido a uma membrana lipoproteica que os envolve (Silva, 1997). Segundo a Instrução Normativa $n^{\circ}$ 62, o teor mínimo aceitável para o leite integral é 3\% de gordura, mantido originalmente do leite natural (Brasil, 2011). Por outro lado, o leite semidesnatado e o desnatado passam por um processo de centrifugação para remover uma fração ou completamente a gordura. A composição de gordura tem de ser mantida entre $0,6 \%$ e $2,9 \%$ para o leite semidesnatado, enquanto permite-se um teor máximo de $0,5 \%$ para o leite desnatado.

$\mathrm{Na}$ indústria de laticínios, análises de rotina são feitas na recepção do leite para classificá-lo conforme seu destino industrial ou comercial, assim como auxiliar na seleção e alimentação do rebanho. Dentre as análises, a avaliação do teor de gordura é de suma importância, pois o pagamento dessa matéria prima, em alguns países, é feito diante a composição em gordura, além de ser um dos requisitos exigidos pela Instrução Normativa $n^{\circ}$ 51 (Brasil, 2002). Atualmente, o método de análise comumente utilizado é o Método de Gerber, que se fundamenta na interação da matéria orgânica com o ácido sulfúrico, exceto a gordura, a qual é separada mediante centrifugação com o auxílio do álcool isoamílico. Porém, com o manuseio de reagentes perigosos, pouca exatidão e as limitações devido à demora na 
obtenção de resultados dessa metodologia, o desenvolvimento de métodos instrumentais com alta capacidade analítica para suprir a demanda de análises, torna-se necessário.

Atualmente, a luz é definida como uma radiação eletromagnética que apresenta particularidades de onda e de uma partícula denominada fóton. Ao incidir sobre a matéria, o conteúdo energético do fóton é assimilado por moléculas absorventes, modificando-as do estado fundamental para o estado excitado, o que aumenta a energia cinética dessas partículas. No entanto, a duração desse estado mais energético é momentânea e o retorno para o estado fundamental resulta na dissipação da energia na forma de calor. Além deste fenômeno, denominado como absorção, a luz pode ser espalhada em um meio heterogêneo. De acordo com Silva (1997), esse processo influencia na cor dos produtos lácteos em virtude da dispersão de luz refletida pelos glóbulos de gordura.

A esfera integradora é uma estrutura esférica revestida por uma superfície com reflexão difusa perfeita. Nesse equipamento, há uma entrada para a radiação luminosa e uma abertura para conectar um fotodetector, utilizado para capturar a luz refletida no interior da esfera e originar a corrente a ser medida por um espectrômetro. Além disso, essa metodologia pode ser utilizada como padrão de trabalho em virtude da baixa incerteza de medição (Bertan e Iano, 2007).

Diante do que foi apresentado, a presente contribuição tem por objetivo analisar a relação do teor de gordura do leite com os valores de coeficiente de absorção e espalhamento, bem como utilizar a esfera integradora para gerar um padrão de referência do laboratório com o propósito de analisar e desenvolver outros equipamentos de medição óptica.

\section{MATERIAIS E MÉTODOS}

O presente estudo foi resultado da parceria entre a Faculdade de Engenharia Química e o Instituto de Física da Universidade Federal de Uberlândia (UFU), sendo o procedimento experimental foi realizado no Laboratório de Imagens Funcionais do Instituto de Física da UFU. A marca do leite UHT integral e desnatado utilizado foi Itambé, lote L01 e M2, respectivamente.

Para realizar as medições na esfera integradora, utilizou-se uma cubeta de vidro de 1 $\mathrm{mm}$ para dispor as amostras no equipamento. A fonte luminosa consistia em uma lâmpada de halogênio. O software Spectra Suite foi utilizado para a leitura de sinais pelo espectrofotômetro. Esses sinais consistiram em valores de transmitância e reflexão em função da faixa de comprimento de onda da luz que a lâmpada emite. Para este trabalho, escolheu-se trabalhar no espectro visível, especificamente na faixa de $500 \mathrm{~nm}$ à $800 \mathrm{~nm}$.

Inicialmente, mediu-se o sinal com a fonte luminosa desligada para remover a influência da luz do ambiente. Em seguida, ligou-se a lâmpada para medir o sinal com a esfera sem a amostra. Esses resultados seriam utilizados como referência para o processamento dos dados. Posteriormente, foram realizadas três medições para cada tipo de leite, etapa ilustrada pela Figura 1. Os resultados obtidos pelo espectrofotômetro foram processados por um algoritmo no software MATLAB para determinar os coeficientes de absorção e espalhamento em função do comprimento de onda para o leite integral e desnatado. 
Figura 1 - Medição da transmitância e reflexão do leite pela esfera integradora

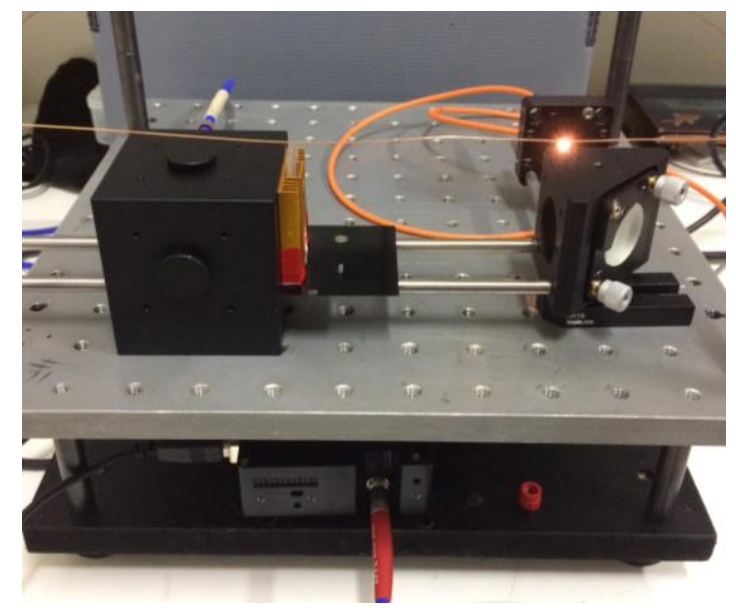

\section{RESULTADOS E DISCUSSÃO}

A Figura 2 ilustra os valores de coeficiente de absorção em função do comprimento de onda para o leite UHT integral e desnatado. Observa-se que o processo de absorção para o leite desnatado não ocorreu com a mesma intensidade que o leite integral, apesar de possuir o mesmo comportamento. Beer, em 1852, observou que o processo de absorção é proporcional à concentração de uma espécie absorvedora (Ball, 2006). Diante disso, os coeficientes de absorção decrescem ao diminuir o teor de gordura.

Figura 2 - Comparação entre os coeficientes de absorção $\left(\mu_{\mathrm{a}}\right)$ para o leite UHT integral e desnatado em função do comprimento de onda

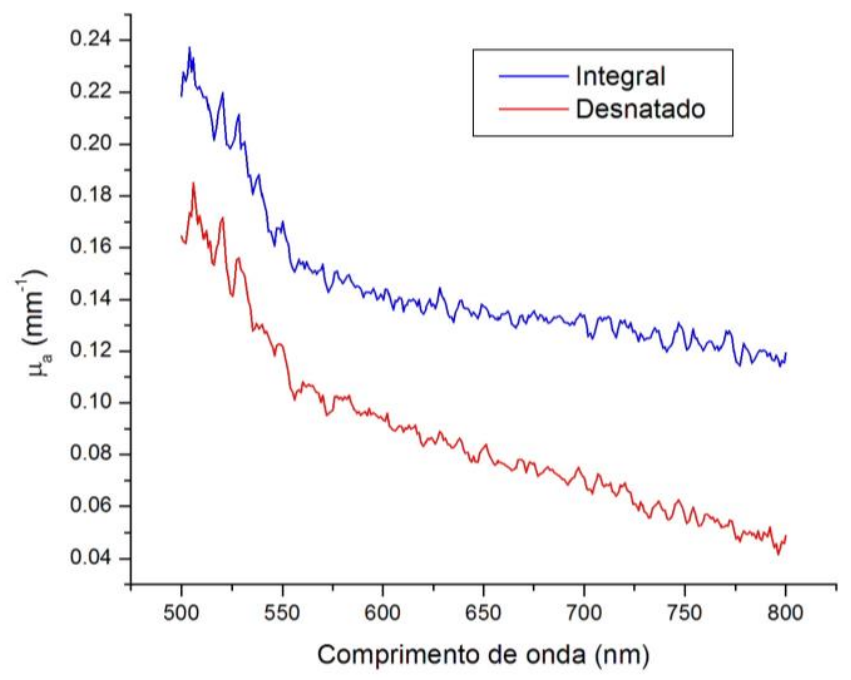

Além disso, observa-se que o decréscimo dos valores de absorção para o leite desnatado é maior com o aumento do comprimento de onda. A faixa entre $650 \mathrm{~nm}$ e $800 \mathrm{~nm}$ pode ser 
utilizada em equipamentos de rápida medição para determinar qualitativamente a gordura, visto que a diferença de absorção entre os dois tipos de leite aumenta em comprimentos de ondas maiores. Já a Figura 3 apresenta o coeficiente de espalhamento em função do comprimento de onda para as amostras. Os resultados ilustrados indicam que o alto teor de gordura resultou no aumento do espalhamento da luz.

Figura 3 - Comparação entre os coeficientes de espalhamento $\left(\mu_{\mathrm{s}}\right)$ para o leite UHT integral e desnatado

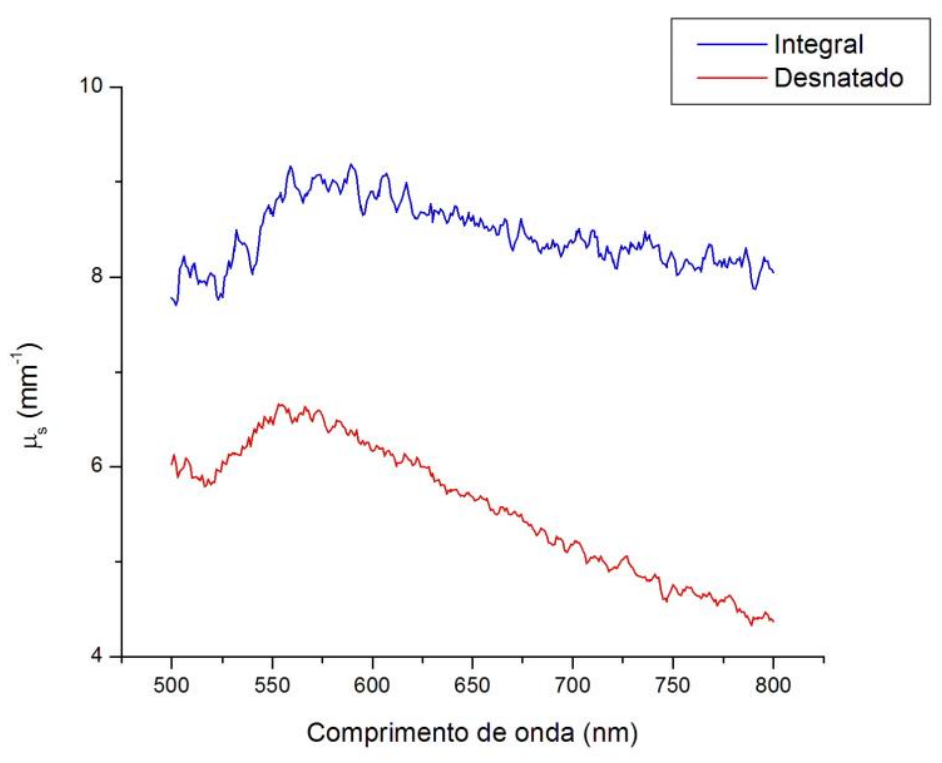

Segundo Aernouts et al. (2015) e Bogomolov et al. (2013), o tamanho do glóbulo de gordura influencia diretamente no coeficiente de espalhamento, principalmente na faixa de $550 \mathrm{~nm}$ a $1100 \mathrm{~nm}$. Diante disso, os valores acentuados de espalhamento próximos ao comprimento de onda de $550 \mathrm{~nm}$ são resultados do espalhamento da luz por glóbulos pequenos de gordura, visto que esse fenômeno para pequenas partículas espalhadoras é mais deslocado para comprimento de ondas menores.

Como esperado, o processo de espalhamento para o leite desnatado diminuiu com o aumento do comprimento de onda, uma vez que os pequenos glóbulos de gordura não interferem no processo de espalhamento em comprimentos de onda maiores, além desse leite possuir um teor de gordura próximo à zero.

\section{CONCLUSÃO}

Este trabalho teve como objetivo analisar o efeito da gordura para os processos de absorção e espalhamento da luz e gerar um padrão de referência para comparar e desenvolver outros equipamentos com sensores ópticos de análises rápidas e precisas. Para essa finalidade, os pontos experimentais foram levantados pela esfera integradora. De forma geral, observouse que o processo de absorção para o leite desnatado não ocorreu da mesma magnitude como para o leite integral, em virtude da proporcionalidade entre o coeficiente de absorção e a concentração da partícula absorvente. Além disso, observou-se também que o tamanho dos 
glóbulos de gordura interferiu significativamente no processo de espalhamento, além do teor de gordura.

\section{REFERÊNCIAS}

AERNOUTS, B; VAN BEERS, R; WATTÉ, R; HUYBRECHTS, T; LAMMERTYN, J; SAYES, W. Visible and near-infrared bulk optical properties of raw milk. J. Dairy. Sci., v. 98, p. 6727-6738, 2015.

BALL, D.W. Field Guide to Spectroscopy. Bellingham, WA : SPIE Press, 2006.

BERTAN, H. H; IANO, Y. Análise de Desempenho da Esfera Integradora para Calibração de Medidores de Potência Óptica. R. Cient. Per. Telec., v. 09, nº 02, 2007.

BOGOMOLOV, A.; MELENTEVA, A.; DAHM, D. J. Technical Note: Fat globule size effect on visible and shortwave near infrared spectra of milk. J. Near Infrared Spectrosc., v. 21, p. 435-440, 2013.

BRASIL. Instrução Normativa $n^{\circ}$ 62. Regulamento Técnico de Identidade e Qualidade de Leite Pasteurizado. Diário Oficial da União, 2011.

BRASIL. Instrução Normativa $n^{\circ}$ 51. Regulamento Técnico de Identidade e Qualidade de Leite Pasteurizado. Diário Oficial da União, 2002.

SILVA, P. H. F. da. Leite: Aspecto, composição e propriedade. Quím. n. Esc., nº, 1997. 